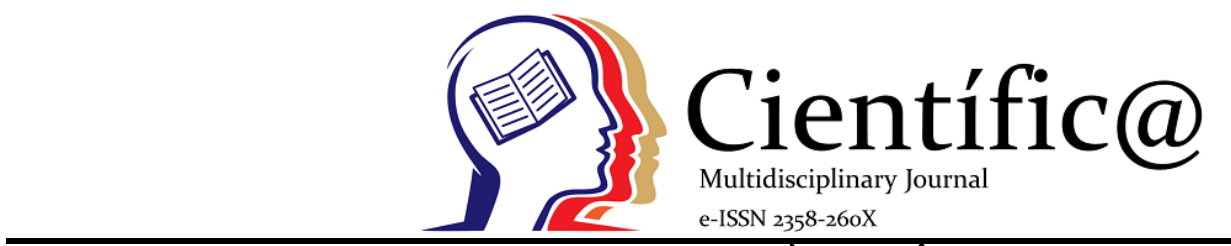

\title{
O USO DAS PLATAFORMAS DE ENSINO Ȧ DISTÂNCIA COMO TECNOLOGIA CAPAZ DE REALIZAR A EXTENSÃO RURAL E O FORTALECIMENTO DO AGRONEGÓCIO
}

\author{
THE USE OF DISTANCE EDUCATION PLATFORMS AS A TECHNOLOGY ABLE TO PERFORM RURAL \\ EXTENSION AND THE STRENGTHENING OF AGRIBUSINESS
}

\author{
Ariele de Mesquita Alves ${ }^{1}$, Mallú de Mendonça Barros ${ }^{2}$
}

\begin{abstract}
${ }^{1}$ Bacharel em Administração - Faculdade Sul-Americana (FASAM). E-mail: ariele.7790@gmail.com
${ }^{2}$ Administradora, Doutoranda em Agronegócios, na linha de pesquisa de Meio Ambiente e Desenvolvimento Regional PPGAGRO-UFG; Mestre em Conservação e Preservação do Cerrado (PPGCRENAC-IFGOIANO); Especialista em Gestão Pública (UFG); Especialista em Planejamento Estratégico, Gestão e Implementação EaD (UFF); Especialista em Docência

Universitária (FacLIONS). Docente Universitária na Faculdade Sul Americana (FASAM) servidora pública lotada na Agência Municipal de Meio Ambiente (AMMA/ Prefeitura de Goiânia), Lattes: CV: http://lattes.cnpq.br/5694875693173557 E-mail: mallumendonca.adm@gmail.com
\end{abstract}

Info

Recebido: 02/2021

Publicado: 03/2021

DOI: 10.37951/2358-260X.2021v8i1.5565

ISSN: 2358-260X

\section{Palavras-Chave}

ead; agronegócio; modalidade de ensino;

profissionalização.

Keywords:

distance learning; agribusiness rural professionalism; improving the rural skills.

\section{Resumo}

Este artigo aborda o uso das plataformas de ensino à distância como tecnologia capaz de realizar a extensão rural e o fortalecimento do agronegócio, a pesquisa fará um apanhado dos últimos anos do Brasil no contexto do agronegócio dos diversos setores econômicos do País, e ainda a contribuição do setor no contexto educacional, razão pela qual, as plataformas de ensino a distância tem contribuído para a formação dos profissionais, conciliando tempo, distância e a acessibilidade de uma educação remota. Esta é uma pesquisa com abordagem qualiquantitativa, que empregou para a coleta dos dados, questionários estruturados para a comparação dos dados obtidos dentre os gestores pesquisados de como a descrever as principais atividades produtivas que realçam a importância do agronegócio brasileiro; compreender o ensino a distância como instrumento de capacitação profissional e os benefícios da tecnologia empregada à distância como capaz de promover o desenvolvimento econômico-social no Estado de Goiás. Para isso, utilizou-se do método comparativo, das respostas gestoras, a partir de um estudo de caso realizado em Goiânia, no Serviço Nacional de Aprendizagem Rural (SENAR) por ser uma empresa de referência nacional e com expertise na formação de profissionais do agronegócio, inclusive pela modalidade a distância (Ead).

\section{Abstract}

This research is about the use of distance learning platforms as a technology capable of achieving rural extension and strengthening agribusiness, the survey will take a look at the last years of Brazil in the context of agribusiness in the various economic sectors of the country, and also the contribution of the sector in the educational context, which is why the distance learning platforms have contributed to the training of professionals, reconciling time, distance and the accessibility of remote education. The research aims to describe the main productive activities that highlight the importance of Brazilian agribusiness, showing how distance learning has been an instrument of professional training as well as the benefits of technology applied to the field as economic and social development.

\section{INTRODUÇÃO}

A história da economia e do desempenho tecnológico brasileiro tem fortes raízes ao agronegócio. Se no período colonial ocorria a exploração de produtos em que o vulto econômico se dava pela comercialização de produtos, como a madeira do pau brasil; dos processos da implantação das lavouras canavieiras e da mecanização das agroindústrias; com o advento da ciência do campo e de novas tecnologia proporcionando a transformação de regiões antes consideradas inadequadas para a agricultura, mas que sobreviviam da agropecuária, como por exemplo, o 
estado de Goiás, agora a tecnologia também se verifica na formação profissional que tem sido propulsora da geração de trabalho, renda e da competitividade tanto no âmbito regional, quanto no cenário nacional,

Em outras palavras, o agronegócio brasileiro que vivencia grandes etapas desenvolvimentistas que não param, principalmente pelo advento da ciência e das inovações tecnológicas desse setor, assiste com a modernização da educação e das metodologias de ensino à distância, uma nova etapa e, dessa vez, que direcionada às ações educativas voltadas para a formação de profissionais que atuarão no campo ou áreas do agronegócio, o que gera grande interesse de um público específico quanto a participação nos programas de formação EAD, engrossando as filas de pessoas capacitadas que possam somar à extensão rural e atuar profissionalmente neste segmento que detém grande parcela de contribuição no produto interno bruto brasileiro (PIB).

Nesse sentido, este estudo visa atender aos seguintes objetivos: descrever as principais atividades produtivas que realçam a importância do agronegócio brasileiro para o mercado internacional; apresentar como a metodologia de ensino a distância tem sido instrumento de capacitação profissional; enumerar os benefícios da tecnologia aplicada ao campo como um instrumento de desenvolvimento econômico-social; apontar as preferências de cursos com base no perfil de estudantes que usam a tecnologia de ensino a distância como forma de profissionalização.

Ademais, este trabalho justifica-se socialmente porque as tecnologias dos programas de educação à distância têm desencadeado grandes transformações na sociedade a partir da instrução e da formação de pessoas, seja na cidade, seja no meio rural, por conta da expansão da educação e da conectividade de grupos interessados que usam da rede da internet como uma forma eficiente de inclusão social, que tem gerado benefícios laborais e melhoria nos processos produtivos, além de novos hábitos de vida no campo. Cientificamente, novos negócios e condições de instrução têm criado condições de flexibilização de estudo e gestão do tempo para que o cursista gerencie seu tempo em prol de ampliar conhecimentos e habilidades profissionais pela EAD que tem sido amparada pela pesquisa científica e por investimentos estruturais na abertura de centros educacionais que dividem mercado e público-alvo com as empresas do ensino tradicional presencial.

Por fim, esta é uma pesquisa comparativa ocorrida no ano de 2020, em que se utilizou no material e métodos, da método da abordagem qualiquantitativa com resultados a partir de um estudo de caso realizado em Goiânia, no Serviço Nacional de Aprendizagem Rural (SENAR) por ser uma empresa de referência nacional e com expertise na formação de profissionais do agronegócio, inclusive pela modalidade a distância (Ead).

\section{FUNDAMENTAÇÃO TEÓRICA}

\subsection{Agronegócio: dos pressupostos históricos ao potencial de desenvolvimento econômico}

De acordo com Renai (2007), a história econômica brasileira tem fortes raízes junto ao agronegócio, uma vez iniciada pela exploração da madeira denominada de Pau Brasil e que se originou o nome do nosso país, isso no século XVI, ainda com base na doação de terras e da monocultura da cana- deaçúcar de regime escravocrata, gerando a expansão do latifúndio e da poupança da agricultura se instalam agroindústrias, como a do vinho e dos móveis, da carne bovina e de suínos e aves e, na década de 1970 e 1990, o agronegócio brasileiro passou por grande impulso, com o desenvolvimento da ciência e tecnologia proporcionando o domínio de regiões antes consideradas inadequadas para a agropecuária. 
O agronegócio ou agrobusiness (em inglês) é o conjunto dos segmentos de insumos para a agropecuária (fertilizantes, medicamentos veterinários, sementes e outros), produção básica (ainda no campo), agroindústria (processamento do leite, produtos vegetais) e agrosserviços (unidades de beneficiamento, prestação de serviços, unidades de comercialização e distribuição e outros). O termo abarca a oferta de um variado número de produtos, sendo considerado como “agricultura tropical”(VALARINHO, 2006).

Isso explica por que agronegócio é responsável pela integração de diversos setores da economia brasileira que estão diretamente ligados aos produtos e subprodutos advindos da atividade agrícola ou pecuária, possibilitando a confecção de roupas, a elaboração de produtos de higiene pessoal, biotecnologias ou que é servido na mesa de todos os brasileiros e recepcionado pelo mercado exterior, como os seguintes produtos: soja, carnes e derivados de animais, açúcar e álcool, madeira (papel, celulose e outros), café, chá, fumo, tabaco, algodão e fibras têxteis vegetais, frutas e derivados, hortaliças, cereais e derivados e a borracha natural são itens importantes na pauta de exportação brasileira (VALARINHO, 2006);

Segundo o IBGE (2005), a região CentroOeste se destaca, sendo o Mato Grosso aquele estado que responde por $27,0 \%$ do total produzido pelo país, seguido de Goiás com 10,9 milhões na produção e soja em Mato Grosso do Sul com 10,2 milhões de toneladas. Isso que representa a geração de U\$ 6,5 trilhões, enquanto no mercado interno esse valor é de $\mathrm{R} \$ 350$ bilhões, ou 26\% do PIB, segundo a Confederação Nacional da Agricultura - CNA(2005); o país ocupa o terceiro lugar no ranking mundial dos exportadores do agronegócio, obtendo a maior taxa de crescimento entre 1990 e 2003 (IMP, 2015).

Apesar do cenário de crise por conta da Covid-19, desde 2015, segundo o MAPA (2015), as projeções das exportações já indicam um aumento de $13,7 \%$ a $59,5 \%$ para frango, de $28,9 \%$ a $110,5 \%$ para carne bovina e de $29,4 \%$ a $87,3 \%$ para suína - haja vista a alimentação é uma necessidade básica e a segurança alimentar pauta do diferentes governos e modelos internacionais, em que os principais compradores deverão ser os Estados Unidos, seguidos de países africanos, da Rússia e do Japão e a produção de grãos deverá passar de 184,2 milhões de toneladas em 2012/2013 para 222,3 milhões em 2023, com potencial de produção que pode chegar a 274,8 milhões de toneladas. Isso significa um acréscimo à oferta entre 20,7\% e 49,2\% na próxima década, o que implica que a área plantada de grãos deverá expandir para até 57,3 milhões de hectares em 2023, além de sua grande competitividade, utilização de alta tecnologia e geração de empregos e riquezas para o país (MAPA, 2015).

\subsubsection{Agronegócio e o Desenvolvimento Regional em Goiás}

Com a política de modernização do setor agropecuário, observa-se em Goiás mudanças em sua estrutura econômica. $\mathrm{O}$ processo de modernização trouxe consigo um conjunto de medidas que favoreceram o agronegócio goiano, com a expansão e incorporação de novas áreas, técnicas mais avançadas e a contribuição de novos investimentos. Houve também o estreitamento das relações entre o setor agrícola e o setor urbano industrial, trazendo assim, o aumento de suas exportações. $\mathrm{O}$ resultado dinâmico do agronegócio, que proporciona a Goiás competividade no cenário nacional, é entre outros fatores, o desenvolvimento de novas tecnologias pela Embrapa e o financiamento rural. Isso possibilitou o crescimento do setor em Goiás (IMB, 2017).

Goiás é a nona economia brasileira com PIB de R $\$ 189$ bilhões, apresentando 2,8\% do PIB nacional. Sua renda per capita resulta em 
R\$27.457,63. Entre 2010 e 2017, o PIB goiano cresceu a uma taxa média de 1,4\% ao ano, desempenho acima do nacional, que ficou e, $0,48 \%$. Este bom desempenho manteve Goiás no seleto grupo das dez maiores economias entre os estados da Federação. Verifica-se que o expansivo resultado se deve à evolução do agronegócio goiano, do comércio e também do crescimento e diversificação do setor industrial. Este setor teve na atividade de alimentos e bebidas, automobilística, fabricação de medicamentos, beneficiamento de minérios e, mais recente, na cadeia produtiva da cana-de-açúcar (IMB, 2015).

A agropecuária é uma atividade econômica importante em Goiás, a produção de carnes e grãos impulsiona as exportações. O estado é o quarto produtor nacional de grãos com uma produção em trono de 22,815 milhões de toneladas, o que representa 9,5\% da produção de grãos brasileiros. A pauta agrícola diversifica-se bastante e é composta principalmente por: soja, feijão, tomate, entre outros produtos. A pecuária goiana também é bastante expressiva $\mathrm{e}$ posiciona o estado entre os maiores produtores do país. O rebanho bovino é o segundo no ranking brasileiro e é formado por 22,8 milhões de cabeças, com participação de 10,6\% no efetivo nacional. A suinocultura e avicultura também se encontram consolidadas, principalmente na região Sudoeste Goiano. O estado se posiciona em ambas, no sexto lugar no ranking nacional, cuja produção representa $5,0 \%$ e 5,3\% da produção brasileira (IMG, 2015).

\subsection{Os modelos de educação tradicional e a} metodologia de ensino à distância $(\mathrm{EaD})$

O ensino a distância inaugura uma oportunidade de profissionalização, atender regiões longínquas da escola presencial e do ensino tradicional, isso porque desde o século IX os sistemas nacionais de ensino consideravam que a educação é o direito de todos e dever do Estado, sendo o professor o detentor do conhecimento que será repassado à humanidade mediante as aulas expositivas, muita teoria, exercícios sistematizados e memorização no modelo de ensino tradicional (MOURÃO, 2008), todavia com a modificação com o surgimento do ensino a distância, destaca Ribas (2010), que "começou no Brasil na década de 30, pela realização de cursos profissionalizantes por correspondência capacitação de colaboradores costuma ser uma prática permanente em empresas".

O grande desafio em fazer o treinamento de trabalhadores não está somente em criar ações para que isso aconteça, mas também em conciliar a agenda de todos os envolvidos no processo, sem afetar muito a produtividade dessas pessoas que se preocupam em se manter atualizados e pronta para superar obstáculos no mercado de trabalho.

"O caminho cultural em direção ao saber é o mesmo para todos os alunos, desde que se esforcem; devem lutar para superar as dificuldades e conquistar um lugar junto aos mais capazes. Caso não consigam, devem procurar um ensino mais profissionalizante."

(GÔNGORA, 1985, p.23).

Nesse contexto, muitas das organizações passaram a adotar essas novas práticas educacionais com vistas a driblar essa falta de tempo e de deslocamento para um curso presencial, o que tornou o Ensino a Distância (EAD) mais popular, além de representar economia de tempo e dinheiro para muitos cursistas. 
Dentre outras vantagens observadas pelos cursistas que investem num curso a distância, verificamse: autonomia quanto a administração e economia de tempo, porque não é preciso convocar outros colaboradores para gerenciar esse treinamento, e podem definir e organizar a sua própria agenda para realizar os estudos; as matérias podem ser disponibilizadas na plataforma (incluindo vídeos explicativos e apresentações de slide). Para o Inep (2018), “em 2016, cerca de 1,5 milhões de brasileiros optavam pelo ensino a distância, enquanto, em 2004, esse contingente era de apenas 60000 ingressantes nessa modalidade $\mathrm{EaD}$, correspondendo a $1,8 \%$ das matrículas totais, conforme se verifica figura 1 , abaixo.

Figura 1 - A evolução da procura de cursos de graduação por EAD: Comparativos dos anos 2004 e 2016

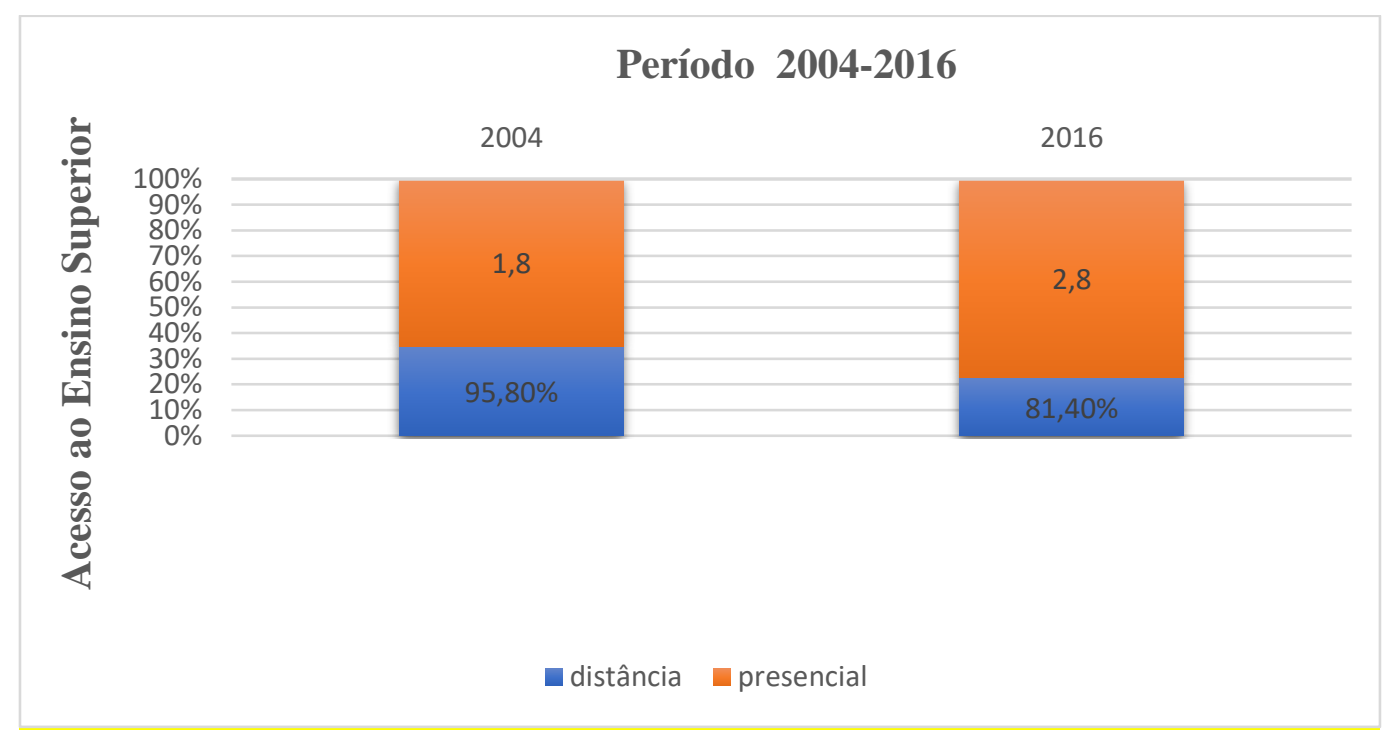

Fonte: INEP/MEC (2018)

De acordo com a Associação Brasileira de Educação a Distância - ABED (2019), dos requisitos mais valorizados nesta modalidade, o preço das mensalidades é um deles, pois podem ser até $65 \%$ mais baratas do que as presenciais. Para a ABED, o valor é justificado pela escala em que os cursos atingem maior número de alunos e o mesmo professor leciona para mais estudantes do que na dinâmica presencial. Nos cursos presenciais houve uma queda de $3,7 \%$ enquanto nos cursos a distância houve um aumento de $21,4 \%$. O crescimento no EAD se deve a dois fatores principais, a flexibilidade e o preço. Outra justificativa é que o curso online o aluno pode estudar onde e quando quiser.
A modalidade também tem aplicado o acesso à educação superior, principalmente para pessoas que vivem em localidades distantes dos grandes centros e não teriam como acessar cursos presenciais, como no caso do meio rural e para a Hoper Educação (2017), a idade mais comum entre os estudantes de ensino superior à distância no Brasil é de 28 anos, enquanto que no presencial, 21 anos. O perfil predominante é de mulheres ingressantes nos cursos EAD, e 86\% das pessoas começam EAD mais de dois anos após o fim do Ensino Médio. 
Figura 2 - Demandas por Cursos de graduação, com metodologia EAD (Ano referência: 2018)

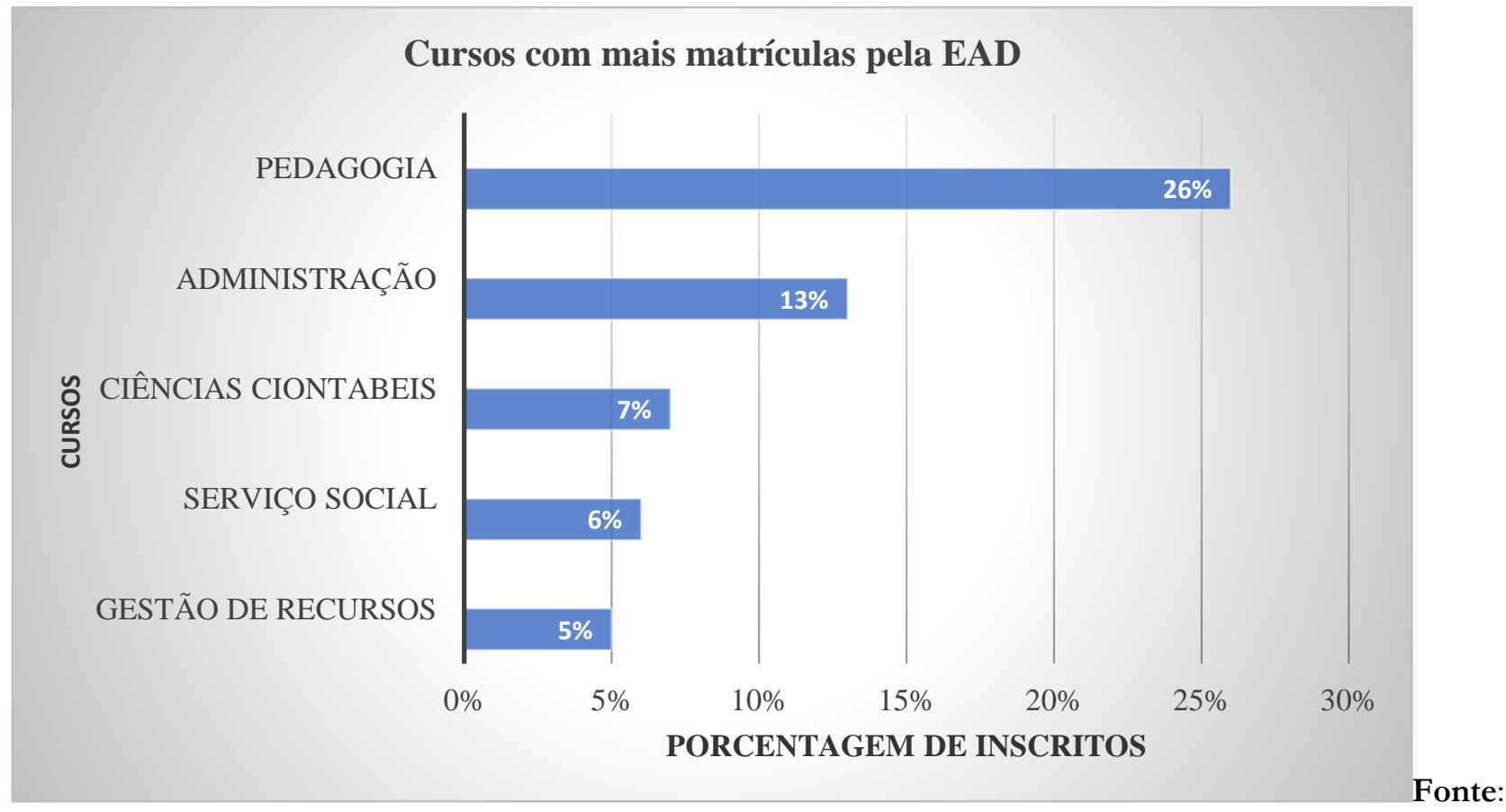

Inep/MEC (2018)

Na Figura 2, pode-se verificar a procura pelos cursos com o maior número de matrículas em ensino a distância. Pedagogia em primeiro, administração em segundo, ciências contábeis em terceiro, serviço social em quarto e gestão de recursos em quinto.

\section{METODOLOGIA (material e métodos)}

\subsection{Das estratégias à definição dos tipos de pesquisa}

A presente pesquisa foi estruturada em duas etapas, sendo que a primeira desse estudo se constitui a partir de uma abordagem descritiva e tem a finalidade de realizar o estudo, a análise, o registro e a interpretação dos fatos do mundo físico sem interferência do pesquisador (Barros \& Lehfeld, 2007). Em outras palavras, será realizada uma pesquisa bibliográfica e uma revisão da literatura a fim de fazer um levantamento que descreve conceitualmente o uso das plataformas de ensino à distância e das definições de tecnologia que sejam capaz a instrução do agronegócio pelos ambientes ambientais virtuais.
Levantamento bibliográfico ou revisão bibliográfica corresponde a pesquisa bibliográfica é o levantamento de toda a bibliografia já publicada, em forma de livros, revistas, publicações avulsas e imprensa escrita.

A sua finalidade é fazer com que o pesquisador entre em contato direto com todo o material escrito sobre um determinado assunto, auxiliando o cientista na análise de suas pesquisas ou na manipulação de suas informações. Ela pode ser considerada como o primeiro passo de toda pesquisa científica (Marconi e Lakatos,1992). 
Por outro lado, segundo Silva (2001) a revisão bibliográfica corresponde o processo de levantamento e análise do que já foi publicado sobre o tema e o problema de pesquisa escolhidos. Permitirá um mapeamento de quem já escreveu e o que já foi escrito sobre o tema.

A revisão bibliográfica é indispensável definição do projeto de pesquisa e para obter uma ideia dos conhecimentos sobre o tema em um estudo, serão realizadas buscas por artigos indexados nas bases de dados do portal de periódicos da Coordenação de Aperfeiçoamento de Pessoal de Nível Superior (CAPES) e Google Acadêmico. Foram pesquisados artigos científicos em língua portuguesa, no lapso temporal de 1990 a 2019 e com as seguintes palavras chaves: "agronegócio", "metodologia de ensino a distância", "EAD".

Será realizado ainda uma abordagem exploratória, haja vista que ser uma pesquisa que visa oferecer informações sobre o objeto desta e orientar a formulação de hipótese (Cervo e Silva, 2006).

Somando a isso, a pesquisa exploratória consiste em investigações de pesquisa empírica cujo objetivo é a formulação de questões ou de um problema, com tripla finalidade: descrever hipóteses; aumentar a familiaridade do pesquisador com $\mathrm{O}$ ambiente, fato ou fenômeno para realização de uma pesquisa futura mais precisa; e modificar e clarificar conceitos (Marconi e Lakatos, 2017).
Nesse sentido, a segunda etapa desse estudo, ocorreu no segundo semestre de 2020, mediante uma pesquisa comparativa, que de acordo com Gil (2008), é o método que procede a investigação com indivíduos, classes, fenômenos ou fatos e vistas a ressaltar as diferenças e as similaridades entre eles. Assim, nesta etapa verificar o atendimento dos objetos desse estudo, e mediante a aplicação de questionários o perfil de alunos que cursam o ensino a distância numa instituição renomada que detém cursos voltados a extensão rural, inclusive em Goiás.

\subsection{A pesquisa de campo, a coleta de dados e a tabulação dos dados}

Para a pesquisa de campo, para validar o método comparativo, foi realizada a partir de um estudo de caso, em empresa especializada em desenvolvimento de talentos no agronegócio e assistência técnica agropecuária e de atuação em todo país.

Os dados foram coletados no Serviço Nacional de Aprendizagem Rural (SENAR), com sede em Goiânia-GO; a aplicação de um questionário semiestruturado se deu aos gestores em 3 níveis de gestão para fins comparativos; Totalizando-se o número amostral da pesquisa compreendeu a 3 gestores, aos quais foram garantidos o sigilo de nomes. Ademais, o questionário foi estruturado com dezoito perguntas, sendo treze perguntas fechadas e cinco perguntas abertas aplicada entre $1^{\circ}$ de agosto à 30 de setembro de 2020, que foram respondidos pelo "Google formulários", por conta do isolamento social devido a pandemia global do COVID-19. Para a tabulação e tratamento dos dados, realizou-se o uso do software do Google formulários e do Excel, pacote do Microsoft Office. 


\section{ANÁLISE E DISCUSSÃO DOS RESULTADOS}

Todos os dados serão obtidos e cuidadosamente analisados, objetivando o cruzamento de informações para descrições plausíveis que posteriormente serão apresentadas em forma de relatórios e gráficos.

A fim de se verificar a literatura acerca da gestão em cursos EAD, como uma metodologia formadora de profissionais na área do agronegócio. Foi realizado um estudo de caso na organização brasileira, do sistema de ensino a distância (EAD), como sendo àquela mais reconhecida acerca da temática apresentado neste estudo: O SENAR - Serviço Nacional de Aprendizagem Rural, o qual autorizou o estudo e fornecimento dos dados, garantido o sigilo das fontes.

Assim sendo, para apresentação dos dados coletados, bem como a discussão dos resultados, serão apresentados 2 momentos: A) Caracterização dos profissionais entrevistados, garantindo-lhes o sigilo dos nomes; B) Apresentação do quadro investigativo, com o rol de perguntas e respectivas respostas.

Quadro 1 - Caracterização dos Gestores de Cursos Profissionalizantes em EAD na Área de Agronegócios

\begin{tabular}{|c|c|c|c|}
\hline $\begin{array}{l}\text { Caracterização dos } \\
\text { entrevistados }\end{array}$ & GESTOR 1 & GESTOR 2 & GESTOR 3 \\
\hline Gênero & Masculino & Masculino & Feminino. \\
\hline Faixa etária & De 31 à 40 anos. & De 31 à 40 anos. & De 41 à 50 anos \\
\hline Estado civil & Casado & Casado & Divorciada \\
\hline $\begin{array}{l}\text { Área } \\
\text { atuação/cargo }\end{array}$ & $\begin{array}{l}\text { Coordenador regional do } \\
\text { SENAR-GO }\end{array}$ & $\begin{array}{l}\text { Coordenação Técnica do } \\
\text { SENAR-GO }\end{array}$ & $\begin{array}{l}\text { Gerente de Educação do } \\
\text { SENAR-GO }\end{array}$ \\
\hline $\begin{array}{l}\text { Tempo no cargo } \\
\text { (EAD) }\end{array}$ & 4 anos & 6 meses & 2 anos \\
\hline
\end{tabular}

Infere-se do Quadro 1 que, dentre os gestores pesquisados em Instituição reconhecidamente atuante nos Cursos Profissionalizantes em EAD na Área de Agronegócios que 02 homens (que equivale a 66,67\%), verificando-se apenas 01 mulher (33,33\%). Todos eles com até 4 anos na organização, sendo que: 1 gestor homem é Coordenador Regional do SENARGO com 4 anos no cargo, o outro gestor homem é Coordenador Técnico do SENAR-Go à 6 meses no cargo e a gestora mulher Gerente de Educação do SENAR-GO à 2 anos no cargo. A maioria dos pesquisados, pertence ao gênero masculino, que alegam ser casados, sendo que: 2 homens pesquisados são casados e sendo uma mulher entrevistada divorciada.
Isso significa ainda que a instituição é aberta para ambos os gêneros sem discriminação, o que garante um cenário moderno e composto por pessoas avaliadas pelas suas competências para os aspectos gerenciais, compostos, portanto, liderado tanto por homens quanto por mulheres. 
Quadro 2 - Caracterização das principais atividades realizadas pelas pessoas que buscam o ensino a distância, bem como as principais atividades produtivas brasileiras

\begin{tabular}{|c|c|c|c|}
\hline PERGUNTAS & GESTOR 1 & GESTOR 2 & GESTOR 3 \\
\hline $\begin{array}{l}\text { Quais as principais atividades } \\
\text { produtivas brasileira? }\end{array}$ & Grãos & Grãos & Grãos \\
\hline $\begin{array}{l}\text { Qual o perfil dos estudantes } \\
\text { que ingressão nos cursos EAD } \\
\text { voltados para o agronegócio? }\end{array}$ & $\begin{array}{l}\text { Aqueles que tem } \\
\text { maturidade e gestão } \\
\text { do tempo. }\end{array}$ & $\begin{array}{l}\text { Aqueles } r \text { que } \\
\text { conciliam estudo e } \\
\text { trabalho. }\end{array}$ & $\begin{array}{l}\text { Os que tem ligação } \\
\text { com a área do } \\
\text { agronegócio. }\end{array}$ \\
\hline $\begin{array}{l}\text { Quais são as principais áreas } \\
\text { do mercado que tem absorvido } \\
\text { esses profissionais? }\end{array}$ & Iniciativa Privada. & Iniciativa Privada. & Outros. \\
\hline $\begin{array}{l}\text { Em qual quesito o ensino EAD } \\
\text { atua eficientemente na } \\
\text { capacitação dos profissionais } \\
\text { do agronegócio? }\end{array}$ & $\begin{array}{ll}\text { Cria profissionais } \\
\text { especialistas } \quad \text { em } \\
\text { áreas técnicas. }\end{array}$ & $\begin{array}{l}\text { Qualificação } \\
\text { profissional. }\end{array}$ & $\begin{array}{l}\text { Facilita a entrada no } \\
\text { mercado de trabalho. }\end{array}$ \\
\hline $\begin{array}{l}\text { Quais preferências de } \text { cursos } \\
\text { no agronegócio r nas } \\
\text { plataformas de ensino (EAD)? }\end{array}$ & Outros. & $\begin{array}{l}\text { Planejamento } \\
\text { estratégico } \\
\text { empresa rural. }\end{array}$ & Outros. \\
\hline $\begin{array}{l}\text { Quais as razões que você } \\
\text { considera da evasão escolar do } \\
\text { curso a distância? }\end{array}$ & $\begin{array}{l}\text { Não adaptação ao } \\
\text { método EAD. }\end{array}$ & $\begin{array}{ll}\text { Choque cultural } \\
\text { diante do } & \text { modelo } \\
\text { pedagógico. } & \end{array}$ & Outros. \\
\hline $\begin{array}{l}\text { Como a tecnologia EAD pode } \\
\text { ajudar no desenvolvimento } \\
\text { social econômico no campo? }\end{array}$ & $\begin{array}{lr}\text { Despertando } & \text { o } \\
\text { interesse } & \text { de } \\
\text { determinado } & \\
\text { público-alvo } & \text { pelo } \\
\text { estudo. } & \end{array}$ & $\begin{array}{l}\text { Despertando de } \\
\text { interesse de de } \\
\text { determinado público- } \\
\text { alvo pelo curso. }\end{array}$ & $\begin{array}{l}\text { Intensificando } \\
\text { sustentabilidade } \\
\text { ambiental. }\end{array}$ \\
\hline
\end{tabular}

Para se avaliar o uso das plataformas de ensino à distância como tecnologia capaz de realizar a extensão rural e o fortalecimento do agronegócio, o quadro 2 foi capaz de ilustrar as principais atividades realizadas pelas as pessoas que buscam o ensino a distância, bem como suas preferências, suas razões, onde o curso EAD atua com eficácia na capacitação destes profissionais, o perfil dos estudantes que ingressão no curso e as razões de evasão do curso, sendo capaz ainda de destacar as principais atividades produtivas brasileira.
Diante disso, pode-se verificar com o gráfico 1 que, para fins de atendimento dos objetivos do estudo demonstra que as principais atividades produtivas brasileira é a de grãos. Sendo que, foram entrevistados 3 gestores, 02 homens $(66,67 \%)$ e 01 mulher $(33,33 \%)$ totalizando um total de $100 \%$ da pesquisa, o que equivale que todos os gestores responderam que a principal atividade produtiva brasileira é a cadeia produtiva de grãos. 
Gráfico 1 - Principais atividades produtivas no cenário do agro no Brasil relevante segundo os gestores entrevistados

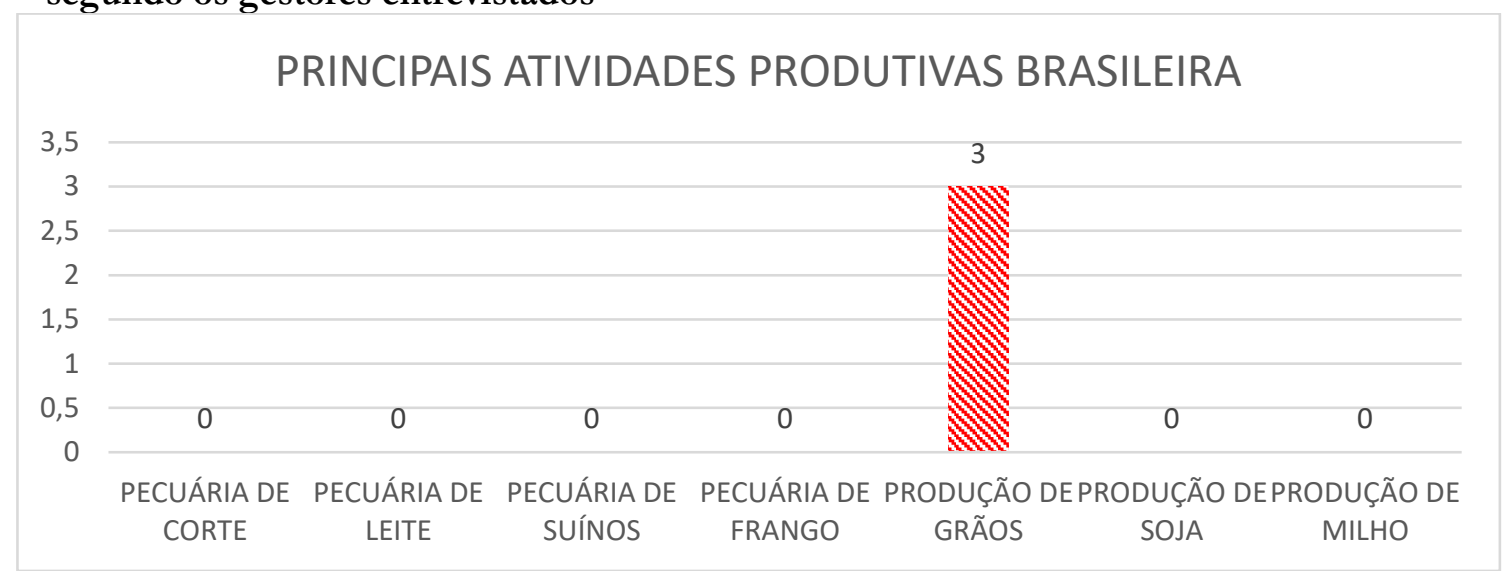

Essas respostas podem ser justificadas, por exemplo, com indicadores como o do Centro de Estudos Avançados em Economia Aplicada (CEPEA, 2018) que em 2017 o PIB Brasileiro havia crescido 1\%, enquanto o PIB-volume do Agronegócio, aumentou $7,2 \%$ impulsionado pela produção recorde "dentro da porteira", pela importante recuperação agroindustrial e pelo consequente "transbordamento" da agropecuária (segmento primário do agronegócio) dado as safras 1990/1991 e 2016/2017, em que a produção brasileira de grãos tinha aumentado $310 \%$, com expressiva elevação média anual de 5,3\%, atingindo recorde histórico de 237,7 milhões de toneladas na última safra.
Ademais, com esse bom desempenho, nas últimas décadas, os grãos puderam contribuir significativamente para a economia brasileira sob diferentes aspectos, de alguma forma retornando à sociedade os investimentos públicos direcionados ao setor, além da visível expansão da produção brasileira que se traduziu em elevada disponibilidade de alimentos, fibras e energia, garantindo o abastecimento interno e ainda um crescente volume de exportação.

Ao pesquisar sobre o perfil dos estudantes que ingressão nos cursos EAD voltados para o agronegócio, verificou-se:

\section{Gráfico 2 - Perfil dos estudantes que ingressam nos cursos EAD voltados para o agronegócio}

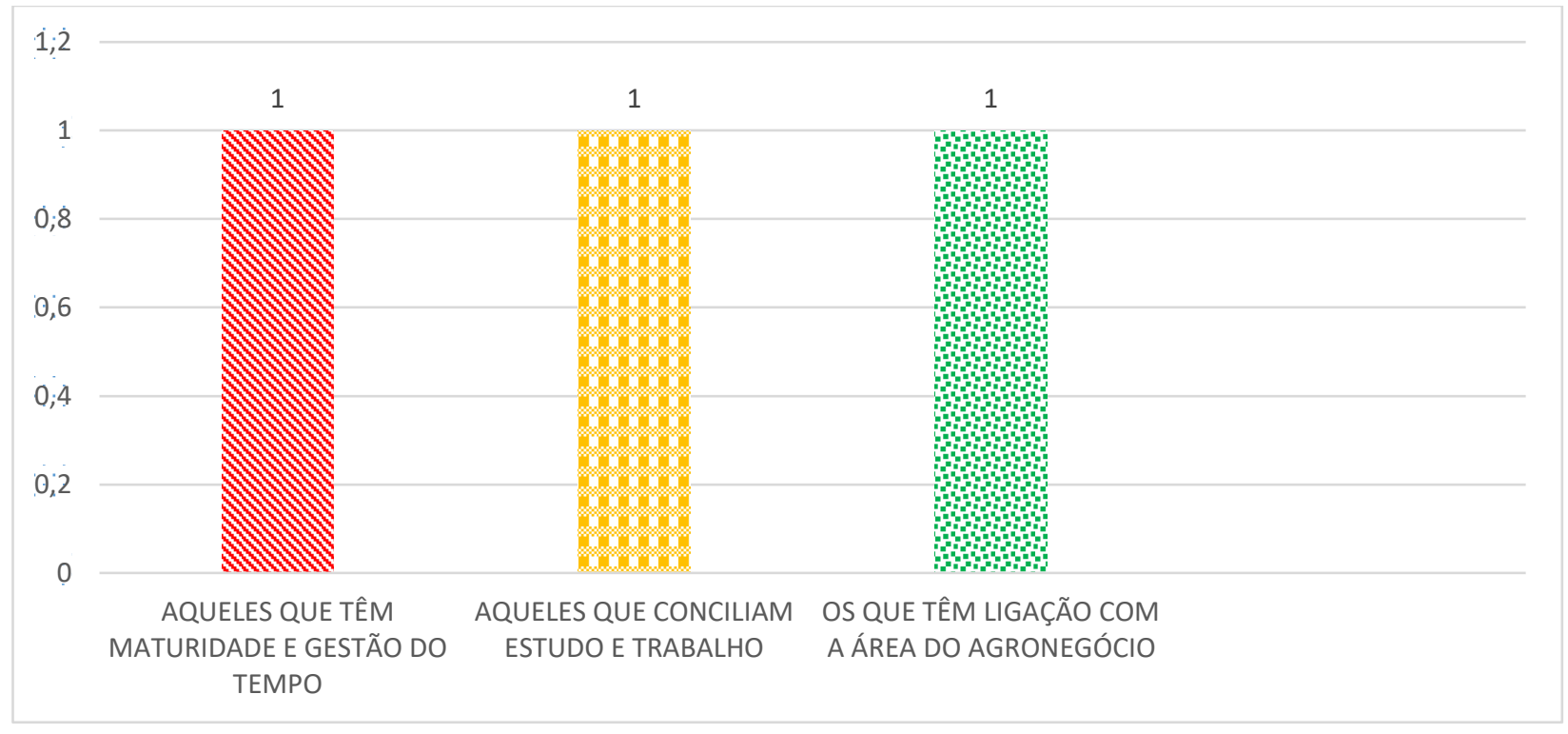


No gráfico 2, observa-se o perfil dos estudantes que ingressão nos cursos EAD voltados para o agronegócio. Sendo 02 gestores homens $(66,67 \%)$ e 01 gestora mulher $(33,33 \%)$. Um gestor homem respondeu que são aqueles que tem maturidade e gestão do tempo que ingressão no curso, outro gestor homem respondeu que são aqueles que conciliam estudo e trabalho e uma gestora mulher respondeu que são aqueles que têm ligação com a área do agronegócio.

Isso justifica, possivelmente, conforme o que prevê a Associação Brasileira de Educação a Distância (ABED, 2016) que o Censo EAD.BR 2016 revelou que a maioria dos alunos de todas as modalidades de cursos estudam e trabalha, características muito acentuadas na EAD. Em 30\% das instituições, mais de $75 \%$ dos alunos de cursos regulamentados totalmente a distância estudam e trabalham. Já nos cursos semipresenciais e presenciais, esse percentual é de $24 \%$. Na avaliação por categoria administrativa, as instituições mais representadas são as ONGs (50\%), na faixa de 76\%-100\% de alunos que estudam e trabalham, seguidas das instituições educacionais privadas com fins lucrativos $(37 \%)$ e das instituições privadas sem fins lucrativos (31\%). Praticamente não há inscrições ofertantes de cursos a distância que tenham indicadores que menos de 25\% dos seus alunos estudam e trabalham. Nesta categoria, encontram-se $6 \%$ dos alunos de instituições privadas sem fins lucrativos.

Ao pesquisar sobre as principais áreas do mercado que têm absorvido esses profissionais, verificou-se:

\section{Gráfico 3 - As principais áreas do mercado que têm absorvido esses profissionais}

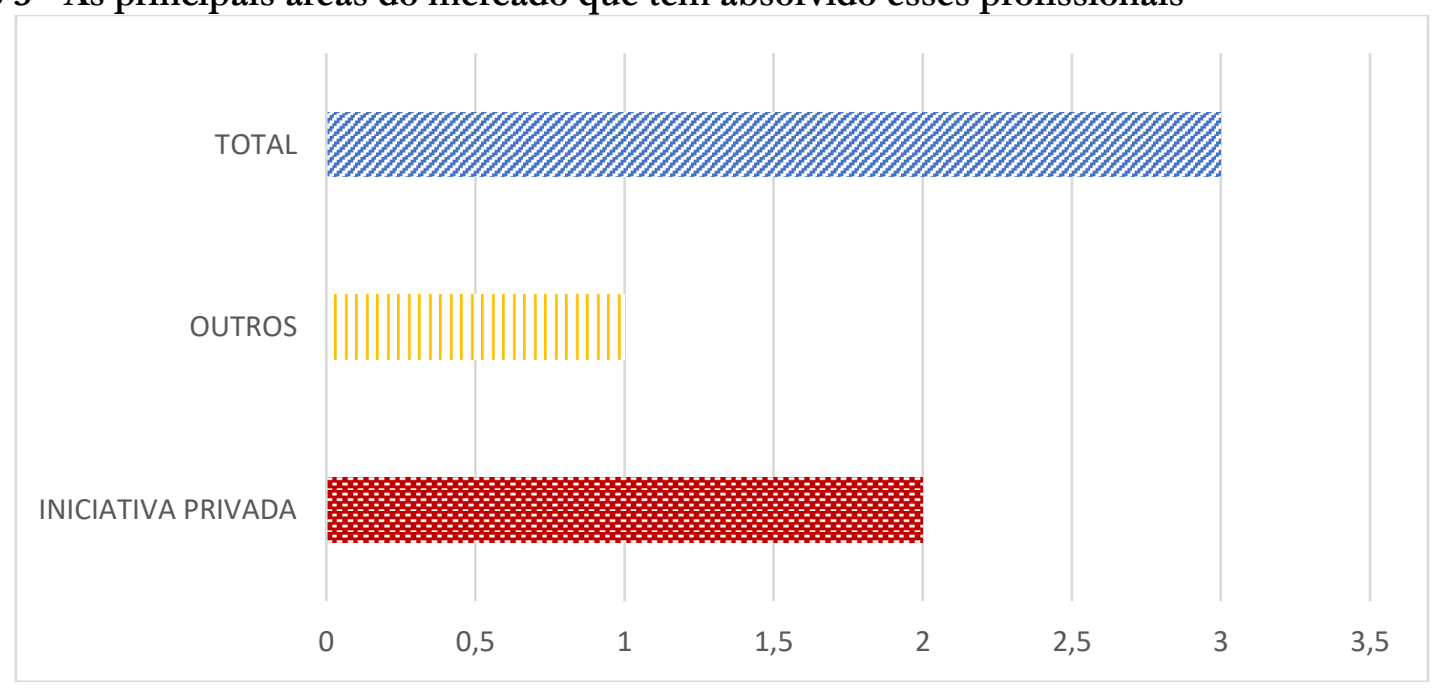

De acordo com o gráfico 3 dos 03 entrevistados, $02(66,67 \%)$ responderam que as principais áreas que têm absorvido esses profissionais que concluem os cursos pelas plataformas EAD são os da iniciativa privada, $01(33,33 \%)$ marcou a opção "outros motivos" e justificando que o profissional capacitado por atuar em variadas áreas do mercado. Isso explica o estudo do CEPEA (2018), “de um total de 18.093.831 empregos no agronegócio no Brasil,
19,8\% do total de pessoas ocupadas no país referem-se a este segmento", sendo uma das áreas que mais contratam, sejam os interessados oriundos de uma formação tradicional presencial, seja ela na Ead.

Diferentemente do caso do PIB, em segmento "serviços" é predominante, no que tange empregos, a "agropecuária" vem em primeiro lugar, com 45,8\%, seguida de "serviços", "indústria" e “insumos, com respectivamente $31,7 \%$ e $1,2 \%$. Sendo a 
agropecuária um cenário que colabora muito nesse processo de contratação, daí o interesse em investir em profissionais qualificados para atuar nessa área.
Ao se pesquisar sobre em qual quesito o ensino EAD atua eficientemente na capacitação dos profissionais do agronegócio, verificou-se:

\section{Gráfico 4 - Qual quesito o ensino EAD atua eficientemente na capacitação dos profissionais do agronegócio}

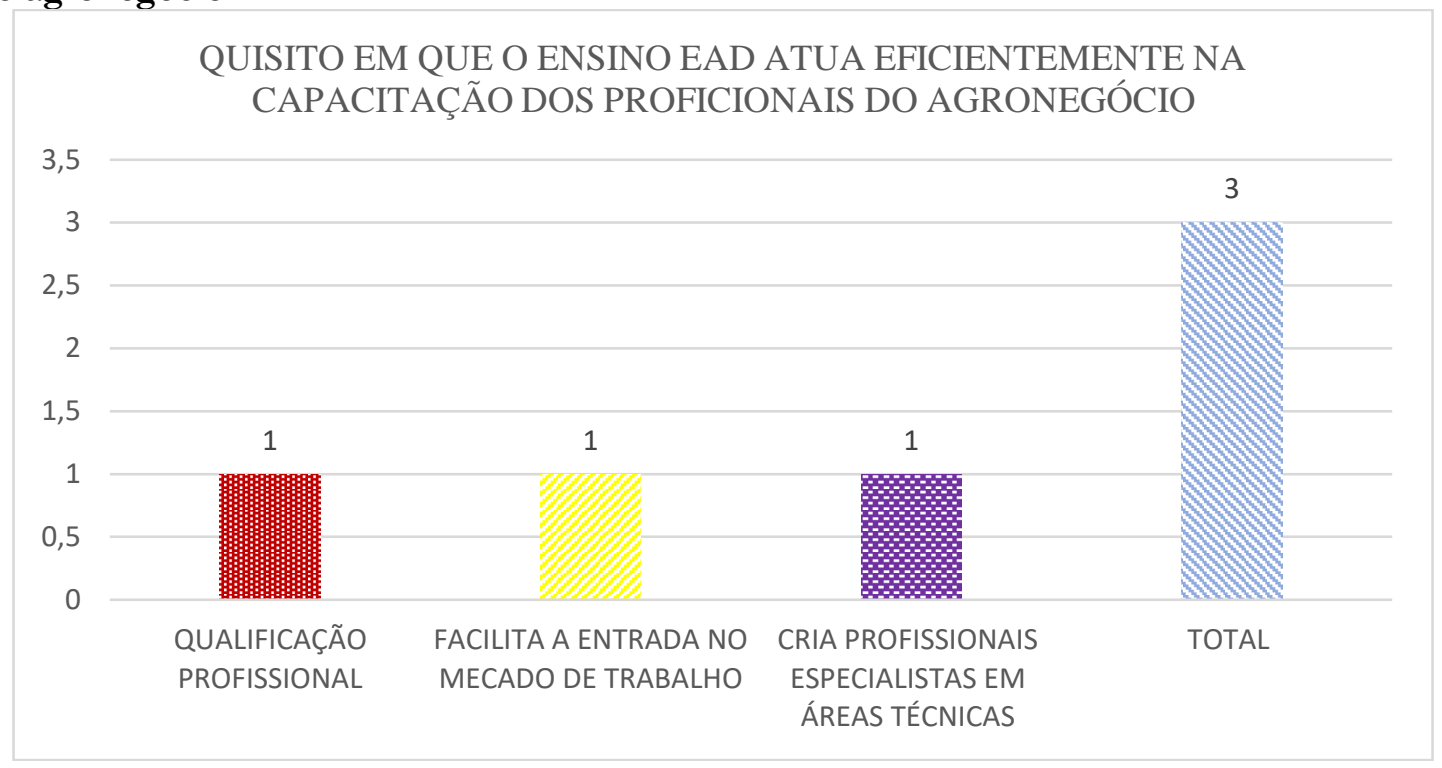

De acordo com o gráfico 4, dos 03 entrevistados, 01 respondeu qual quesito o ensino $\mathrm{EAD}$ atua eficientemente na capacitação dos profissionais do agronegócio é a qualificação profissional, 01 respondeu que facilita a entrada no mercado de trabalho e o último marcou cria profissionais especialistas em áreas técnicas.

Isso explica o que a Revista Dinheiro Rural (2019), aponta sobre a última década, em que graças as plataformas on-line de comunicação e uma melhor conectividade no campo, novos rumos têm sido desenhados numa dimensão mais robusta, visto que hoje, há 1,6 mil cursos de EAD formalizados pelo Ministério da Educação, com atuação em inúmeras disciplinas, tendo matriculados 1,5 milhão de alunos, metade do público dos cursos universitários presenciais.

Ainda de acordo com a Revista Dinheiro Rural (2019), os cursos à distância podem ajudar a acelerar os processos de gestão nas propriedades rurais, que com a disseminação do conhecimento, o EAD pode contribuir para aumentar a renda no campo. Um exemplo é a Empresa SLC Agrícola, com 18 fazendas nos estados de Mato Grosso, Mato Grosso do Sul, Bahia, Goiás, Piauí e Maranhão, é um exemplo de demanda por EAD, a qual sempre apostou em treinamento de sua equipe de 3,5 mil funcionários quer intensificar esse trabalho por meio da plataforma online. A melhoria está relacionada aos resultados financeiros. Os cursos e treinamentos da equipe baixaram a rotatividade e mão de obra para 15\% no ano passado. Em 2018, a receita líquida da SLC foi de R \$ 2,1 bilhões, 13\% acima de 2017, resultado de 404 mil hectares de cultivo de algodão, soja e milho. O lucro bruto também cresceu, chegando a $\mathrm{R} \$ 406,5$ milhões, um aumento de $10 \%$ no período.

Ao se pesquisar quais as preferências de cursos no agronegócio nas plataformas de ensino EAD, constatou-se: 
Gráfico 5 - As preferências de cursos no agronegócio nas plataformas de ensino (EAD)

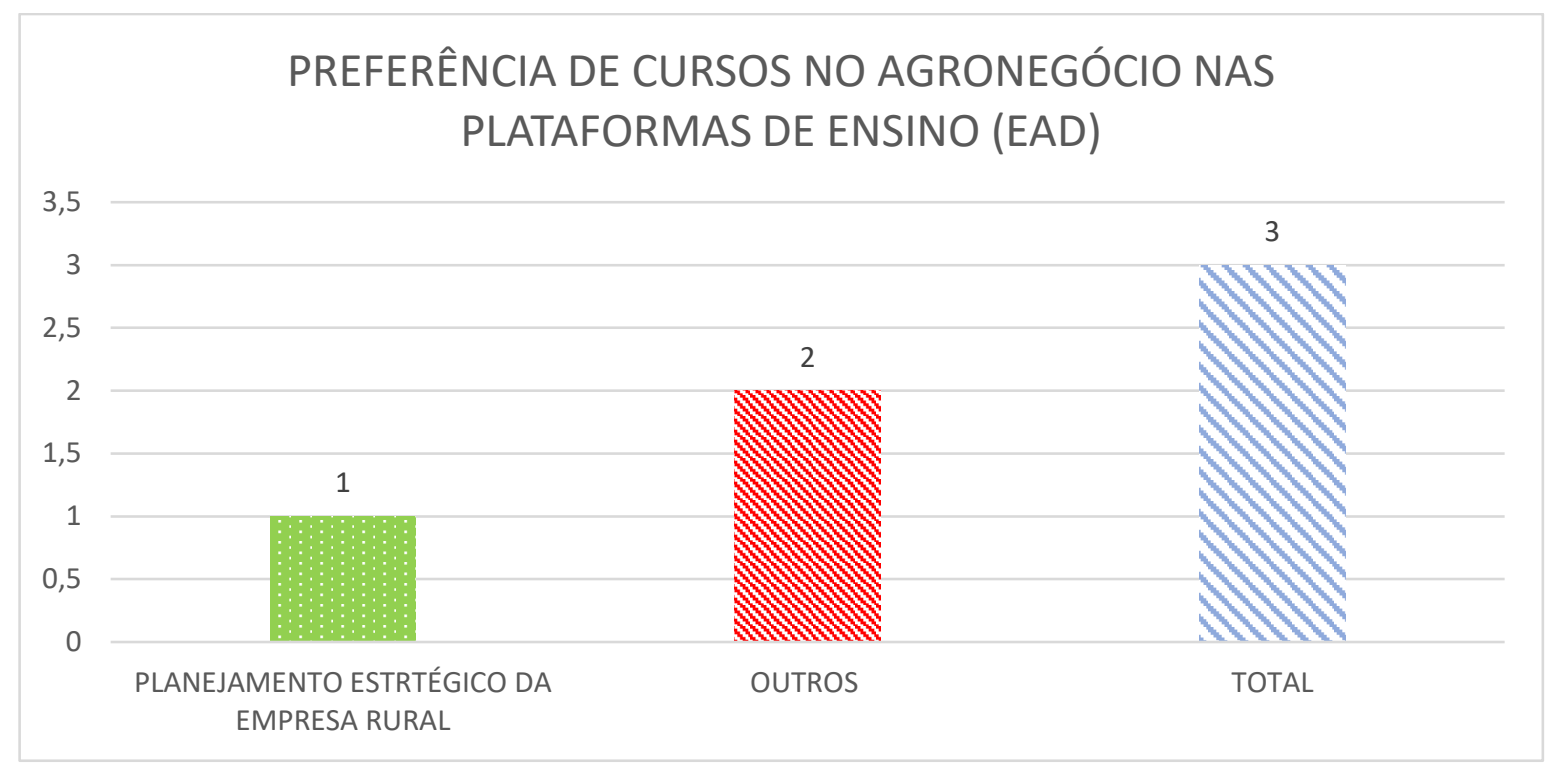

De acordo com o gráfico 5, dos 03 entrevistados, apenas 01 respondeu quais preferências de cursos no agronegócio nas plataformas de ensino EAD é o planejamento estratégico da empresa rural e 02 entrevistados marcaram a opção "outros motivos", e responderam que técnicas para produção, cursos de programa da produção vegetal e os que são voltados ao uso de tecnologias como o de GPS.

Isso justifica de acordo com a Revista Exame (2018), responsável por 23,5\% do PIB brasileiro em 2017, o agronegócio oferece boas perspectivas profissionais. Em 2017, foi responsável por mais de 44\% das exportações brasileiras, que superam 96 bilhões de dólares. Segundo estimativa da Confederação da Agricultura e Pecuária do Brasil (CNA), o setor contribuiu com 23,5\% em 2017, a maior participação em 13 anos. Diante deste quadro positivo, a busca por profissionais qualificados e experientes disparou, as contratações no agronegócio aumentaram em 25\% entre 2016 e 2017. A procura por cursos e treinamentos específicos para atuar na área também está crescendo, já que atualmente o agronegócio exige profissionais mais qualificados do que no passado.

Ao se pesquisar quais as razões que você considera que seja as causas da evasão do curso a distância (EAD), verificou-se:

\section{Gráfico 6 - Razões da evasão do curso a distância}

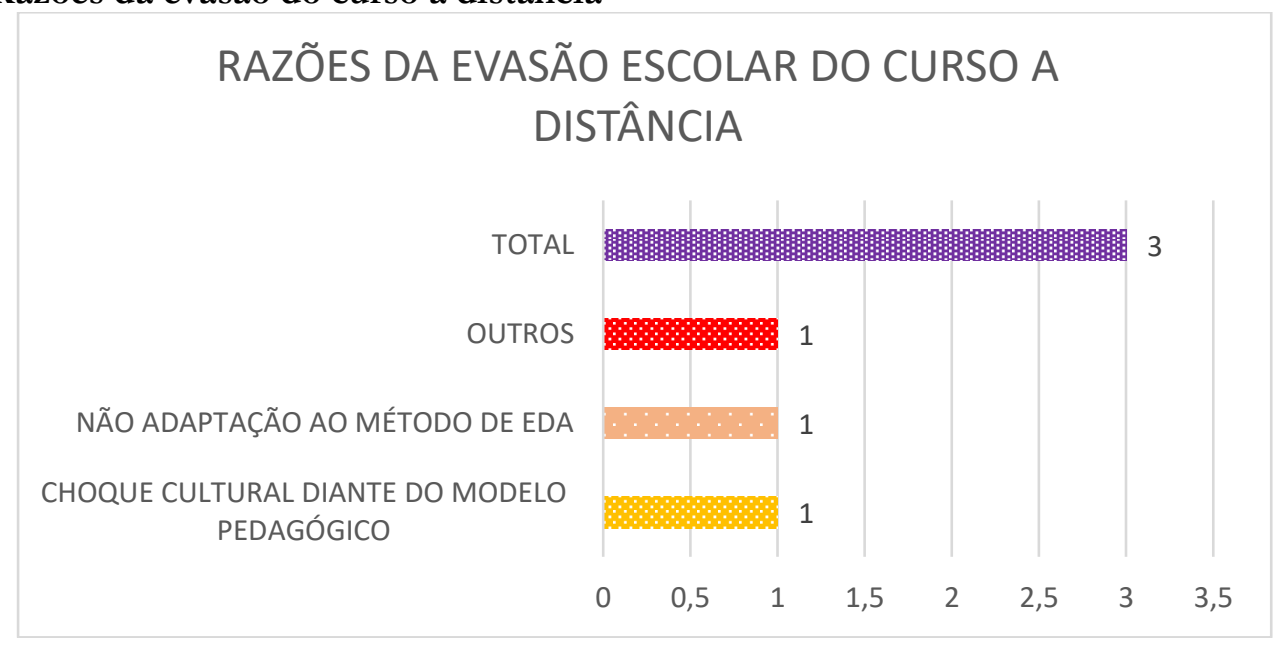


Infere-se do gráfico 6, em que se dos 03 entrevistados, 02 responderam quais as razões que considera que sejam as causas da evasão do curso a distância é a não adaptação ao método de EAD e o choque cultural diante do modelo pedagógico, sendo 01 que respondeu "outros motivos", e justificou a resposta dizendo que a causa é a má gestão do tempo e que muitos cursistas não têm disciplina para conciliar trabalho e estudo. Esse resultado se coaduna a pesquisa da Revista Educação Pública (2017), “um dos fatores que contribuíram para a evasão foi a conciliação de trabalho e estudos 40,7\%, organização do tempo 26,9\%, distância do polo $21,7 \%$ e interação com tutor e aluno, 63\% têm algum tipo de problema na abordagem junto ao tutor, quanto efetuada como forma de interação".

Ao pesquisar como a tecnologia EAD pode ajudar no desenvolvimento social econômico no campo, verificou-se:

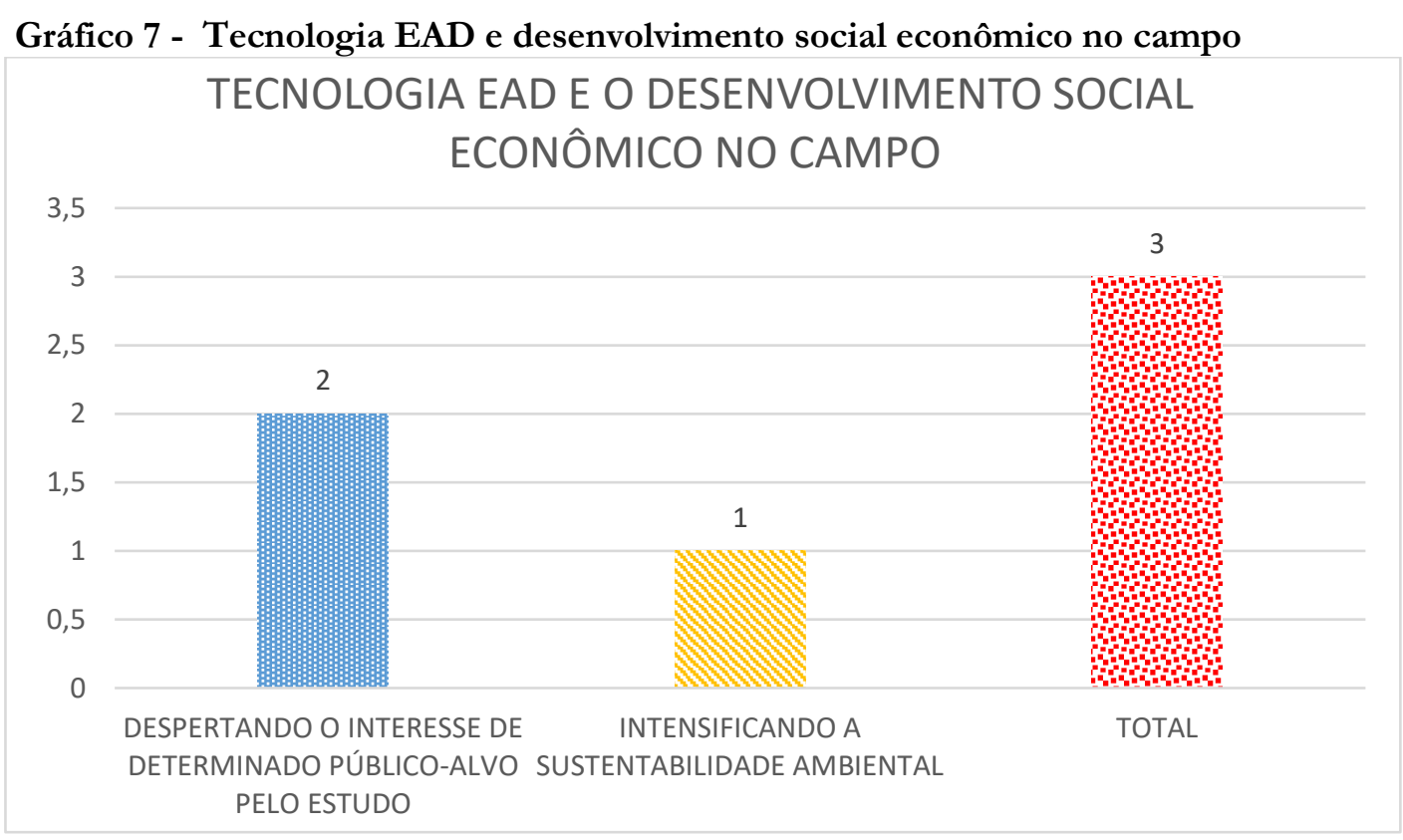

De acordo com o gráfico 7, dos 03 entrevistados responderam como a tecnologia EAD pode ajudar no desenvolvimento social econômico no campo, 02 responderam que é o despertamento do interesse de determinado público-alvo pelo estudo e 01 respondeu que é intensificando a sustentabilidade ambiental.

\section{CONSIDERAÇÕES FINAIS}

Os resultados obtidos nesse estudo, demonstraram o uso das plataformas de ensino à distância como tecnologia capaz de realizar a extensão rural e o fortalecimento do agronegócio. As formas de ensino vêm mudando e devido essas mudanças as plataformas de ensino a distância (EAD) tem contribuído cada vez mais para a formação de profissionais. Dessa forma, realizando a extensão rural e o fortalecimento do agronegócio, em que se verificou a sinergia e a contribuição do ensino a distância (EAD) como facilidade de acesso aos cursos de interesse do agro no Brasil.

Os objetivos do estudo foram atingidos uma vez que obteve-se a enumeração das principais atividades produtivas que realçam a importância do agronegócio brasileiro para o mercado internacional, sendo o setor de grão aquele que mais têm sido o foco dos cursos Ead no setor do agro; por apresentar como a metodologia de ensino a distância tem sido 
instrumento de capacitação profissional, a partir do estudo de caso do SENAR, e da forma de gestão adotada por esta instituição especializada em assistência técnica e formação profissional; foram enumerados os benefícios da tecnologia aplicada ao campo como um instrumento de desenvolvimento econômico-social, como qualificação profissional e áreas de atuação; apontados as preferências de cursos com base no perfil de estudantes que usam a tecnologia de ensino a distância como forma de profissionalização.

Além disso, o estudo considerou a relevância da profissionalização via EaD nas repercussões econômicas e desenvolvimentistas do agronegócio para Goiás, das condições de estudos e do atendimento das demandas de locais e de pessoas interessadas na formação e nas condições deste tipo de trabalho capazes de gerar recursos, qualificação e empregabilidade.

Diante das grandes contribuições do ensino EaD, ainda há desafios quanto as resistências por essa metodologia e preferência cultural pelo modelo presencial, o que pode ser explicado pela dificuldade de conciliar trabalho e, por isso, contribuído quanto a evasão escolar, visto que é preciso alguma assiduidade e desenvolver uma rotina de estudos que exige maior disciplina por parte do aluno. Por fim, a recomendação técnica, diante desta pesquisa comparativa é que para a adoção e a difusão de práticas mais resilientes no agronegócio, precisa-se considerar o fator cultural e local, o que demandaria novos estudos comparativos por unidades federadas brasileiras mediante novas pesquisas que despertem a atenção investidores acerca desta temática.

\section{REFERÊNCIAS}

ABED. Quanto um curso EAD é mais vantajoso que o presencial. Disponível em: < http://abed.org.br/blog/quanto-um-curso-ead- e-mais-vantajoso-que-um-presencial/>. Acesso em: 3.Abr.2020

BARros, A. J. de; LEHFELD, N. A. de. Projeto de pesquisa: proposta metodológica. 4. ed. Petrópolis, RJ: Vozes, 2000a.

CERVO, A. L.; SILVA, R. de. Metodologia científica. São Paulo: Prentice Hall, 2006.

IBGE. Goiás -Visão geral. Disponível em: $<$ https://www.imb.go.gov.br/index.php?option $=$ com_content\&view $=$ article\&id $=79 \&$ Itemid $=$ 145\#sumario>. Acesso em: 2.Abr.2020

\section{CEPEA. Mercado de trabalho do agronegócio brasileiro. 2018b. Disponível em: $<$ https://www.cepea.esalq.usp.br/br/mercado- de-trabalho-do-agronegocio.aspx $>$. Acesso em: 25.Out. 2020}

CEPEA. O crescimento do agronegócio realmente tem se refletido em maior renda para agentes do setor? 2018. Disponível em: < https://www.cepea.esalq.usp.br/br/opiniaocepea/o-crescimento-do-agronegociorealmente-tem-se-refletido-em-maior-rendapara-agentes-do-setor.aspx $>$. Acesso em: 26.Out.2020

GÔNGORA, F. C. Tendências Pedagógicas na Prática Escolar. São Paulo: Edições Loyola, ABED. Censo EAD-BR 2016: Relatório analítico da aprendizagem a distância no Brasil. 2016. Disponível em: < http://abed.org.br/censoead2016/Censo EAD 2016 portugues.pdf $>$. Acesso em: 27. Out.2020 1985.

HOPER EDUCAÇÃO. O que diz o censo da educação superior 2017. Disponível em: > https://www.hoper.com.br/post/2018/09/24/ o-que-diz-o-censo-daeduca $\% \mathrm{C} 3 \% \mathrm{~A} 7 \% \mathrm{C} 3 \% \mathrm{~A} 3 \mathrm{O}-$-superior-2017>. Acesso em: 30.Maio.2020

LAJOLO, M.. EAD 1,5 milhão estuda a distância no Brasil. Disponível em: <https://meuartigo.brasilescola.uol.com.br/ed ucacao/a-pedagogia-tradicional-ontem-

LAKATOS, E.M.; MARCONI, M. de A. Fundamentos de metodologia científica.3.ed. [rev. ampl.]. São Paulo: Atlas, 1991. 270p.

LAKATOS, E.M.; MARCON, M. de A. Fundamentos 
de metodologia científica. 6. Ed. 5. reimp. São Paulo: Atlas, 2007. hoje.htm>. Acesso em: 05.Abr.2020

LOURENÇO, J. C. A evolução do agronegócio brasileiro no cenário atual. Disponível em: $<$ https://administradores.com.br/artigos/aevolucao-do-agronegocio-brasileiro-no-cenarioatual>. Acesso em: 9.Abr.2020

MEC. O que diz o censo da educação superior 2017. Disponível em: $<$ https://www.hoper.com.br/singlepost/2018/09/24/O-QUE-DIZ-O-CENSODA-EDUCA $\%$ C3\%87\%C3\%83O-

SUPERIOR-2017>. Acesso em: 21.Maio.2020

MESQUITA, A. S. O agronegócio brasileiro e suas particularidades. Disponível em: $<$ http://www.seagri.ba.gov.br/sites/default/file s/socioeconomia3_v7n2.pdf $>$. Acesso em: 1.Abr. 2020

MOURÃO, H. A pedagogia tradicional ontem e hoje. Disponível em: <https://meuartigo.brasilescola.uol.com.br/ed ucacao/a-pedagogia-tradicional-ontemhoje.htm>. Acesso em: 3.Abr.2020

PERFAN. A importância do agronegócio no Brasil. $<$ http:/ /blog.perfarm.com/agronegocio-nobrasil/>. Acesso em: 01.Abr.2020

RENAI. A Rede Nacional de informações sobre o Investimento. O Setor de Agronegócio no Brasil: História e Evolução do Agronegócio Brasileiro. Disponível em: < http://investimentos.desenvolviemnto.gov.br/ intern>. Acesso em: 9.Abr.2020

REVISTA DINHEIRO RURAL. Educação sem limites. 2019. Disponível em: < https://www.dinheirorural.com.br/educacaosem-limites/>. Acesso em: 27.Out.2020

REVISTA EDUCAÇÃO PÚBLICA. A evasão na EAD: Uma análise sobre os dados e relatórios, ano base 2017, apresentados pelo Inep, UAB e Abed. 2017. Disponível em: $<\underline{\text { https://educacaopublica.cecierj.edu.br/artigo }}$ s/20/3/a-evasao-na-ead-uma-analise-sobre-osdados-e-relatorios-ano-base-2017-apresentadospelo-inep-uab-e-abed >. Acesso em: 27.Out.2020

REVISTA EXAME. Conheça as 4 carreiras mais quentes do agronegócio brasileiro. 2018. Disponível em: https://exame.com/carreira/conheca-as-4carreiras-mais-quentes-do-agronegocio$\underline{\text { brasileiro/> }}$. Acesso em: 28.Out.2020

RIBAS, M. R. Educação à distância. Disponível em:

$<$ http//www.universitario.com.br/noticias/n.p hp?!10360>. Acesso em: 02.Abr.2020

VILARINHO, M. R. Questões sanitárias e o agronegócio brasileiro. Disponível em:

\section{$<$}

